International Journal of

Environmental Research and

Public Health

ISSN 1660-4601

www.mdpi.com/journal/ijerph

Review

\title{
Gain-Framed Messages Do Not Motivate Sun Protection: A Meta-Analytic Review of Randomized Trials Comparing Gain-Framed and Loss-Framed Appeals for Promoting Skin Cancer Prevention
}

\section{Daniel J. O’Keefe * and Daisy Wu}

Department of Communication Studies, Northwestern University, 2040 Campus Drive, Evanston, IL 60208, USA; E-Mail: YujingWu2014@u.northwestern.edu

* Author to whom correspondence should be addressed; E-Mail: d-okeefe@northwestern.edu; Tel.: +1-847-491-3581; Fax: +1-847-467-1036.

Received: 18 April 2012; in revised form: 30 May 2012 / Accepted: 30 May 2012 /

Published: 5 June 2012

\begin{abstract}
Persuading people to undertake actions to prevent skin cancer is an important public health challenge. A number of studies have compared the effectiveness of gain-framed and loss-framed appeals in this domain, often expecting gain-framed appeals to be more persuasive. A meta-analytic review ( $k=33, N=4,168)$, however, finds no significant difference in the persuasiveness of gain- and loss-framed appeals for encouraging skin cancer prevention. This conclusion is unaffected by differences in the specific protective action advocated or by differences in the kind of outcomes invoked. But the results offer an intimation that men might be more susceptible to framing variations in this domain — with loss-framed appeals potentially having a persuasive advantage.
\end{abstract}

Keywords: skin cancer prevention; message framing; gain-framed; loss-framed; persuasive messages; meta-analysis

\section{Introduction}

Skin cancer is a serious disease. One estimate is that almost 200,000 people worldwide were diagnosed with malignant melanoma in 2008 [1]. In the United States alone, the American Cancer 
Society's estimate is that 12,190 deaths (9,180 from melanoma and 3,010 from other nonepithelial skin cancers) will occur in 2012 [2]. CDC's National Program of Cancer Registries listed the skin as one of the top ten cancer sites in 2008 in the U.S. population [3]. The total number of people in the US population with nonmelanoma skin cancer has been estimated to have been over 3.5 million in 2006, making it an "underrecognized epidemic" [4].

It is correspondingly important to identify what sorts of persuasive messages might be most effective in encouraging skin cancer prevention. One choice faced by advocates is whether to use a gain-framed appeal, which emphasizes the desirable consequences of undertaking the recommended preventive actions, or a loss-framed appeal, which emphasizes the undesirable consequences of failing to undertake the recommended actions.

The most well-known hypothesis about message framing persuasive effects is that the relative persuasiveness of gain-framed and loss-framed messages will vary depending on the kind of behavior being advocated. Specifically, the expectation has been that loss-framed appeals will be more persuasive than gain-framed appeals where the advocated action is a disease detection behavior, but gain-framed appeals will be more persuasive than loss-framed appeals where the advocated action is a disease prevention behavior [5,6]. This general hypothesis has not fared well, however. For most disease detection behaviors, there is no difference in the persuasiveness of gain-framed and loss-framed messages [7]. Similarly, for most disease prevention behaviors, there is no difference in the persuasiveness of gain-framed and loss-framed messages [8]. However, even if these broad categories of behavior do not yield the expected differences, those differences might still emerge in some more specific behavioral domain, such as skin cancer prevention.

This paper provides a meta-analytic review of the accumulated research concerning the relative persuasiveness of gain-framed and loss-framed messages for encouraging skin cancer preventive behaviors. The primary research question is whether gain-framed and loss-framed appeals are differentially persuasive on this subject. Plainly, if one appeal form is generally more effective than the other, those charged with designing messages on this topic will be able to craft messages in ways that maximize effectiveness. No previous message framing meta-analysis located more than a dozen studies concerning skin cancer prevention [8-10]. However, as will be seen, over 30 relevant studies are available (over twice as many as ever previously reviewed), which means that any previous conclusions would have been based on only a fraction of the relevant research evidence.

In addition to addressing the question of whether there is a general difference in the persuasiveness of gain-framed and loss-framed messages in this domain, we were also interested in exploring the possible moderating roles of three variables. One was the advocated action. Any number of different behaviors might be encouraged as a means of reducing skin cancer risk: using sunscreen, avoiding sun exposure at peak times, wearing protective clothing, and so forth. It might be that the relative persuasiveness of gain- and loss-framed appeals varies across different advocated actions.

A second was the basis of the persuasive appeal, that is, the kind of outcomes invoked by the appeal. Skin cancer preventive behaviors might be encouraged by emphasizing the dangers of skin cancer (or other health-related consequences)_or those behaviors might be encouraged by invoking appearance-related consequences of unprotected sun exposure, such as unattractive skin. It might be that the relative persuasiveness of gain- and loss-framed appeals varies depending on the basis of the appeal. 
A third was the sex of message recipients. Even though gain- and loss-framed appeals do not generally differ in persuasiveness, a small but statistically significant loss-framed advantage has been reported for studies in which messages advocated breast cancer detection behaviors [7]. This advocacy subject might be thought distinctive on any number of grounds, but given that all of the research participants in those studies were women, it is at least possible that men and women differ in their susceptibility to message framing variations.

\section{Methods}

\subsection{Identification of Relevant Investigations}

\subsubsection{Literature Search}

Research reports were located through personal knowledge of the literature, examination of reference lists from previous reviews and primary research reports, and searches of relevant databases (including Medline, PsycINFO, EBSCO, ProQuest Dissertations and Theses, ABI/INFORM, and Web of Science) using appropriate combinations of search terms such as message framing, gain-framed, loss-framed, skin cancer, sunscreen, and sun avoidance.

\subsubsection{Inclusion Criteria}

Studies selected had to meet three criteria. First, the study had to be a randomized trial comparing the persuasiveness of gain-framed and loss-framed messages. A gain-framed message emphasizes the advantages of compliance with the advocated view; a loss-framed message emphasizes the disadvantages of noncompliance. Second, the messages had to advocate skin cancer preventive behaviors (e.g., sunscreen use, minimization of sun exposure, etc.). Third, appropriate quantitative data relevant to persuasive effects (e.g., attitude, intention, or behavior) had to be available; where it was not provided in the report, we made efforts to obtain information from authors. Excluded by these criteria were studies of other kinds of framing variations (e.g., [11,12]), studies lacking an appropriate outcome variable [13], and studies for which relevant quantitative information could not be obtained [14-18].

\subsection{Outcome Variable and Effect Size Measure}

The outcome variable was persuasion, as assessed through attitude, behavioral intention, behavior, and the like. When multiple indices of persuasion (e.g., assessments of attitude and intention) were available, we averaged the effects to yield a single summary. Every comparison between a gain-framed message and its loss-framed counterpart was summarized using $r$ (correlation) as the effect size measure. Differences indicating greater effectiveness with gain-framed messages were given a positive sign. When correlations were averaged (e.g., across several indices of persuasiveness), we computed the average using the $r$-to-z-to- $r$ transformation procedure, weighted by $n$. 


\subsection{Moderator Variables}

\subsubsection{Advocated Behavior}

We distinguished studies based on the behavior being recommended by the message. In nearly all studies, the messages mentioned sunscreen use, but some messages advocated only sunscreen use. Hence we contrasted studies in which the messages advocated sunscreen use and studies in which in the messages advocated either some other protective action (e.g., sun avoidance) or multiple actions (e.g., both sunscreen and sun avoidance).

\subsubsection{Appeal Basis}

We distinguished studies based on the kinds of outcomes that formed the basis of the persuasive appeals. In nearly all studies, the messages mentioned health-related outcomes, but some messages mentioned only health-related consequences. Hence we contrasted studies in which the messages invoked only health-related outcomes (e.g., skin cancer) and studies in which the messages did not invoke only health-related outcomes (appeals that referred to other outcomes such as appearancerelated effects, or appeals that invoked a combination of health-related outcomes and other outcomes).

\subsubsection{Message Recipient Sex}

For each study for which appropriate exact information was available, we recorded the proportion of female participants.

\subsection{Unit of Analysis and Meta-Analytic Procedures}

The unit of analysis was the message pair, that is, the pair composed of a gain-framed message and its loss-framed counterpart. We recorded a measure of effect size for each distinguishable message pair found in the body of studies. Whenever a study included more than one message pair and reported data separately for each pair, each pair was treated as providing a separate effect size estimate (e.g., [19]).

In some cases, the same primary data served as the basis for multiple reports (e.g., both a dissertation and a subsequent publication). When a given investigation was reported in more than one outlet, it was treated as a single study and analyzed accordingly. The same research was reported (in whole or in part) in: [20] and ([21], Study 2); [22] and [23]; [24], [25], and [26]; [27] and [28]; [29] and [30]; [31] and [32]; [33] and [34]; [35] and [36]; [37] and [38]. The individual effect sizes (correlations) were analyzed using random-effects procedures (specifically, those of [39]).

\section{Results}

\subsection{Sample Characteristics}

Precise data were not available for most cases concerning the racial/ethnic composition of the study samples, although when such data were reported the samples were predominantly Caucasian. Most participants were young adults (e.g., university students). 


\subsection{Overall Effects}

Effect sizes were available for 33 cases, with 4,168 participants. Details for each included case are contained in Table 1. Across all 33 cases, the random-effects weighted mean correlation was -0.020 . The limits of the $95 \%$ confidence interval for this mean were -0.060 and 0.019 , indicating no significant persuasive advantage for one framing form over the other $(Z=-1.002, p=0.316)$.

Table 1. List of cases.

\begin{tabular}{|c|c|c|c|}
\hline Study & $r$ & $N$ & Codings $^{a}$ \\
\hline Block (1993) sun exposure [20] & 0.174 & 58 & $2 / 1 /$ na \\
\hline Cox, Cox, \& Zimet (2006) Study 1 prevention [40] & 0.013 & 139 & $2 / 1 / 41$ \\
\hline Currie (2010) [41] & 0.064 & 131 & $1 / 2 / 73$ \\
\hline Detweiler et al. (1999) [42] & 0.122 & 217 & $2 / 2 / 76$ \\
\hline Fischer \& Nabi (2001) sunscreen [43] & -0.191 & 79 & $1 / 1 / 54$ \\
\hline Hoffner \& Ye (2009) [28] & 0.000 & 154 & $1 / 1 / 66$ \\
\hline Hwang, Cho, Sands, \& Jeong (in press) [23] & -0.099 & 219 & $2 / 2 / 45$ \\
\hline $\mathrm{Ku}(2008)$ skin cancer $[44]$ & -0.155 & 467 & $2 / 1 / 45$ \\
\hline Lee \& Aaker (2004) Experiment 2 promotion [45] & 0.055 & 85 & $1 / 2 /$ na \\
\hline Lee \& Aaker (2004) Experiment 2 prevention [45] & -0.173 & 78 & $1 / 2 /$ na \\
\hline Lee, Brown, \& Blood (2000) sunscreen/clothing [46] & 0.119 & 132 & $2 / 1 /$ na \\
\hline Lemieux, Hale, \& Mongeau (1994) vivid high fear [19] & 0.039 & 51 & $2 / 1 /$ na \\
\hline Lemieux et al. (1994) pallid high fear [19] & 0.132 & 50 & $2 / 1 /$ na \\
\hline Lemieux et al. (1994) vivid low fear [19] & 0.070 & 50 & $2 / 2 /$ na \\
\hline Lemieux et al. (1994) pallid low fear [19] & 0.019 & 50 & $2 / 2 /$ na \\
\hline McCormick (2010) [47] & -0.114 & 154 & $1 / 2 /$ na \\
\hline Nan (2011) [30] & 0.059 & 152 & $2 / 2 /$ na \\
\hline Robinson (2004) Study 1 [48] & -0.013 & 96 & $1 / 2 / 100$ \\
\hline Rothman et al. (1993) Experiment 2 [18] & 0.039 & 108 & $2 / 1 /$ na \\
\hline Saadi (2009) Experiment 1 prevention disincentive [49] & 0.183 & 50 & $1 / 2 /$ na \\
\hline Saadi (2009) Experiment 1 prevention incentive [49] & -0.137 & 50 & $1 / 2 /$ na \\
\hline Schubert (2008) [50] & -0.131 & 174 & $2 / 2 /$ na \\
\hline Seo (2008) verbal [31] & 0.191 & 48 & $1 / 2 /$ na \\
\hline Seo (2008) visual [31] & -0.162 & 47 & $1 / 2 /$ na \\
\hline Shamaskin (2009) Study 1 skin cancer prevention [33] & -0.165 & 49 & $2 / 1 / 59$ \\
\hline Shen (2005) Study 1 skin cancer [35] & -0.054 & 286 & $2 / 2 / 73$ \\
\hline Shen \& Kollar (2011) sunscreen [51] & 0.125 & 148 & $1 / 2 /$ na \\
\hline Shen \& Kollar (2011) tanning [51] & -0.051 & 143 & $2 / 2 /$ na \\
\hline Smith (2003) prevention [52] & -0.008 & 31 & $2 / 2 /$ na \\
\hline Stoner (2010) [37] & 0.110 & 136 & $2 / 1 / 100$ \\
\hline Taber (2010) [53] & -0.101 & 146 & $2 / 1 / 60$ \\
\hline Thomas et al. (2010) appearance [26] & -0.079 & 183 & $2 / 2 /$ na \\
\hline Thomas et al. (2010) health [26] & -0.144 & 207 & $2 / 1 /$ na \\
\hline
\end{tabular}

\footnotetext{
${ }^{\mathbf{a}}$ The codings are, respectively, the advocated behavior $(1=$ sunscreen, $2=$ other/multiple $)$, the basis of the appeals $(1=$ health consequences only, $2=$ other/multiple), and the proportion of female participants (na $=$ not available).
} 
This result was based on combining outcome data across attitudinal, intention, and behavioral outcomes - thereby affording greater statistical power for detecting any effects - but the substantive conclusion is unaffected by this procedural decision. In this dataset, as in other meta-analytic reviews of the relative persuasiveness of gain-loss message framing variations (e.g., $[9,10]$ ), these different outcomes were functionally equivalent as indicators of relative persuasiveness. Specifically: The mean ES for attitudinal outcomes $(-0.017, k=18,95 \%$ CI limits of -0.078 and .044$)$ did not significantly differ from the mean ES for intention outcomes $(-0.013, k=30,95 \%$ CI limits of $-0.055,0.029$; $\mathrm{Q}(1)=0.010, p=0.921)$ or from the mean ES for behavioral outcomes $(0.044, k=3,95 \%$ CI limits of -0.140 and 0.225 ; $\mathrm{Q}(1)=0.371, p=0.543$ ). The mean ES for intention outcomes did not significantly differ from the mean ES for behavioral outcomes $(\mathrm{Q}(1)=0.344, p=0.558)$.

\subsection{Moderating Factors}

\subsubsection{Advocated Behavior}

The relative persuasiveness of gain-framed and loss-framed appeals was not affected by whether the messages advocated only sunscreen use (mean $r=-0.013$ ) or advocated other or multiple behaviors (mean $r=-0.023$ ); these two mean effects were not significantly different $(Q(1)=0.058, p=0.810)$.

\subsubsection{Appeal Basis}

The relative persuasiveness of gain-framed and loss-framed appeals was not affected by whether the messages invoked only health-related consequences (mean $r=-0.024$ ) or did not invoke only health-related consequences (i.e., invoked non-health consequences or a combination of health and non-health consequences; mean $r=-0.015)$; these two mean effects were not significantly different $(Q(1)=0.048, p=0.826)$.

\subsubsection{Message Recipient Sex}

Twelve cases provided exact information about the proportion of female participants. For exploring the possible moderating role of participant sex, we analyzed the data in two ways. First, we performed a modified weighted least squares regression using the proportion of female participants (as a continuous variable) to predict effect size. Using SPSS regression analysis, and applying the corrections described by [54], the proportion of female participants was strongly $(R=0.635)$ and significantly $(z=3.00, p=0.001)$ related to effect size: As the proportion of female participants increased, effect sizes became more positive.

Second, we dichotomized the 12 relevant cases on the basis of the proportion of female participants. As indicated in Table 2, when the proportion of female participants was greater than 0.6, there was no significant difference in the persuasiveness of gain-framed and loss-framed appeals (mean $r=0.033$, $k=6$ ), but when the proportion of female participants was 0.6 or less, loss-framed appeals were significantly more persuasive than gain-framed appeals (mean $r=-0.119, k=6$ ). These two mean effects were significantly different $(Q(1)=13.194, p=0.001)$. 
Table 2. Summary of results.

\begin{tabular}{|c|c|c|c|c|c|c|}
\hline & $k$ & $N$ & mean $r$ & $95 \% \mathrm{CI}$ & Power $^{\mathrm{a}}$ & $Q(\mathrm{df})$ \\
\hline All cases & 33 & 4,168 & -0.020 & $-0.060,0.019$ & 0.99 & $47.8(32) *$ \\
\hline \multicolumn{7}{|c|}{ Advocated behavior } \\
\hline sunscreen & 12 & 1,120 & -0.013 & $-0.085,0.060$ & 0.64 & $15.4(11)$ \\
\hline other/multiple & 21 & 3,048 & -0.023 & $-0.071,0.025$ & 0.97 & $31.8(20) *$ \\
\hline \multicolumn{7}{|l|}{ Appeal basis } \\
\hline health & 13 & 1,776 & -0.024 & $-0.094,0.046$ & 0.84 & $23.2(12) *$ \\
\hline other/multiple & 20 & 2,392 & -0.015 & $-0.061,0.032$ & 0.93 & $23.5(19)$ \\
\hline \multicolumn{7}{|c|}{ Proportion of females } \\
\hline$>60 \%$ & 6 & 1,020 & 0.033 & $-0.030,0.096$ & 0.61 & $5.1(5)$ \\
\hline$\leq 60 \%$ & 6 & 1,099 & -0.119 & $-0.177,-0.060$ & -- & $3.7(5)$ \\
\hline
\end{tabular}

\section{Discussion}

Gain-framed and loss-framed appeals do not generally differ significantly in persuasiveness concerning skin cancer prevention. The lack of a statistically significant difference is not the consequence of poor statistical power. On the contrary, for detecting even a relatively small population effect $(r= \pm 0.10)$, the data in hand afforded power of 0.99 . One can be quite sure that if any nonzero population effect exists, it is quite small indeed.

This is unquestionably a disappointing result, because identifying dependable ways of substantially enhancing the persuasiveness of skin cancer prevention messages is an important enterprise. But it is plain that those charged with the task of designing skin cancer prevention messages should generally not spend time worrying about whether their messages are gain-framed or loss-framed.

This conclusion is unaffected by the specific preventive action being recommended. There is no evidence that the relative persuasiveness of gain-framed and loss-framed appeals varies as a consequence of whether the message advocates simply sunscreen use or advocates some other action or combination of actions. And this conclusion is unaffected by the kinds of consequences invoked by the message's arguments. Specifically, there is no reason to suppose that the relative persuasiveness of gain-framed and loss-framed messages varies as a consequence of whether the messages invoke only health-related consequences (such as skin cancer) or invoke other consequences (in addition to, or instead of, health consequences).

However, these negative conclusions must be tempered a bit by the intriguing result concerning the sex of message recipients. The very limited evidence in hand suggests that as the proportion of male message recipients increases, loss-framed appeals become progressively more advantageous than gain-framed appeals. More specifically, when the audience is predominantly female, message framing variations make virtually no difference-but with a larger proportion of men in the audience, a difference between gain- and loss-framed messages emerges, with loss-framed appeals having a persuasive advantage.

It is not obvious what might explain this apparent effect. The effect is not plausibly a matter of men somehow being intrinsically more susceptible to message framing variations than are women. 
As mentioned above, a small but statistically significant difference between gain- and loss-framed appeals has appeared in studies in which all the participants were women (studies concerning breast cancer screening behaviors) [5]. It may simply be that this result is a statistical fluke; one notices, for example, the relatively poor statistical power in the set of studies in which the proportion of female participants exceeded 0.6.

This explanatory uncertainty may be seen to reflect the key limitation of the present review (a limitation common to meta-analytic reviews), namely, that the conclusions are necessarily circumscribed by the nature of the primary research under investigation. Given that the observed sex-related effect may be a statistical oddity (given the relatively low power), only additional primary research can provide clarification. As another example: Nearly all of the samples in these studies were composed of college-age participants. Although this population is of natural interest as a focus for skin cancer prevention efforts, this restriction means that one cannot say with confidence how the results might have been different had a broader age range been sampled.

\section{Conclusions}

These results suggest three broad conclusions. First, gain-framed and loss-framed appeals do not generally differ in persuasiveness concerning skin cancer prevention. Researchers interested in developing understandings of what makes for more and less effective messages in this domain should consider directing their efforts elsewhere.

Second, researchers who do continue testing potential differences in the persuasiveness of gain-framed and loss-framed messages concerning skin cancer prevention might attend closely to the sex composition of their samples. The present results raise the possibility of sex-related variations in the differential persuasiveness of gain- and loss-framed appeals, so further evidence will be welcomed.

Third, replications are essential in studies of the relative effectiveness of alternative public health messages. One of the earliest studies of message framing and skin cancer prevention - the research of Detweiler et al. [42] — compared one gain-framed brochure and one loss-framed brochure, and reported that the gain-framed message was more effective. This experimental design is the conventional one for addressing research questions concerning the relative effectiveness of two message kinds: one specific concrete message of one type is compared to one specific concrete message of the other type. But the result obtained in this study was obviously not general. Across 33 such comparisons to date, gain-framed and loss-framed messages are actually statistically indistinguishable with respect to persuasiveness concerning skin cancer prevention. This pattern of effects - in which an initial study produces a statistically significant effect but subsequent research fails to confirm it-is not uncommon [56,57]. Thus in addition to serving as a reminder to be cautious about the conclusions to be drawn from any single study, the present results underscore the importance of replications.

However, it should be noticed that where the research question concerns the relative persuasiveness of two message kinds (e.g., gain-framed vs. loss-framed messages), replications can be created within the design of a single experiment. That is, rather than conducting an experiment examining just one pair of messages (as is the current practice), a researcher could instead compare multiple message pairs. Such designs require statistical analyses adapted to the presence of message replications, but obviously have substantial benefits with respect to establishing dependable generalizations about 
message effects [58-60]. Thus in future research aimed at examining the relative effectiveness of two message kinds for encouraging skin cancer prevention (or any other behavior), the research community need not wait for replications to be published; researchers can - and arguably should-be asked to include message replications in their designs, so as to provide evidence that any claimed effects generalize beyond that particular pair of messages.

\section{Acknowledgments}

Thanks to Hyunyi Cho, Anthony Cox, Sinéad Currie, Cynthia Hoffner, Angela Lee, Natalie Robinson, Yvonne Saadi, Andrea Shamaskin, and Lijiang Shen for providing information about their research.

\section{Conflict of Interest}

The authors declare no conflict of interest.

\section{References}

1. Cancer Research UK. Key Facts: Skin Cancer; Cancer Research UK: London, UK, 2012.

2. American Cancer Society. Cancer Facts \& Figures; American Cancer Society: Atlanta, GA, USA, 2012.

3. US Cancer Statistics Working Group. United States Cancer Statistics: 1999-2008 Incidence and Mortality Web-Based Report; U.S. Department of Health and Human Services, Centers for Disease Control and Prevention and National Cancer Institute: Atlanta, GA, USA, 2012.

4. Rogers, H.W.; Weinstock, M.A.; Harris, A.R.; Hinckley, M.R.; Feldman, S.R.; Fleischer, A.B.; Coldiron, B.M. Incidence estimate of nonmelanoma skin cancer in the United States, 2006. Arch. Dermatol. 2010, 146, 283-287.

5. Rothman, A.J.; Salovey, P. Shaping perceptions to motivate healthy behavior: The role of message framing. Psychol. Bull. 1997, 121, 3-19.

6. Salovey, P.; Schneider, T.R.; Apanovitch, A.M. Message Framing in the Prevention and Early Detection of Illness. In The Persuasion Handbook: Developments in Theory and Practice; Dillard, J.P., Pfau, M., Eds.; Sage Publications: Thousand Oaks, CA, USA, 2002; pp. 391-406.

7. O'Keefe, D.J.; Jensen, J.D. The relative persuasiveness of gain-framed and loss-framed messages for encouraging disease detection behaviors: A meta-analytic review. J Commun. 2009, 59, 296-316.

8. O'Keefe, D.J.; Jensen, J.D. The relative persuasiveness of gain-framed and loss-framed messages for encouraging disease prevention behaviors: A meta-analytic review. J Health Commun. 2007, 12, 623-644.

9. Ak1, E.A.; Oxman, A.D.; Herrin, J.; Vist, G.E.; Terrenato, I.; Sperati, F.; Costiniuk, C.; Blank, D.; Schünemann, H. Framing of health information messages. Cochrane Database Syst. Rev. 2011, doi: 10.1002/14651858.CD006777.pub2.

10. Gallagher, K.M.; Updegraff, J.A. Health message framing effects on attitudes, intentions, and behavior: A meta-analytic review. Ann. Behav. Med. 2012, 43, 101-116. 
11. Leygue, C.; Chappé, J.; Meyer, T.; Verlhiac, J.F. Health information framing and ambivalent attitudes toward sun exposure. Health Psychol. Rev. 2007, 1, doi:10.1080/17437190701472504.

12. Real, K.; Rimal, R.N. Assessing the Importance of Skin Cancer: Effects of Frames of Reference and Issue Involvement. Presented at The Annual Meeting of the International Communication Association, Washington, DC, USA, 22-26 May 2001.

13. Knapp-Oliver, S.; Aunaetitrakul, N.; Toh, G.; Sapkota, S.; Penny, T. Message Framing Influences Cognitive Processing and Retention of Information Regarding Skin Cancer. Presented at The 23rd Annual Association for Psychological Science Convention, Washington, DC, USA, 24-27 May 2011.

14. Buboltz, W.; Mahoney, K.T.; Walzcyk, J. Reactance and Message Frames: Does it Matter? Presented at The Fourteenth Annual Meeting of the American Association of Behavioral and Social Sciences, Las Vegas, NV, USA, 10-11 February 2011.

15. Craciun, C. Motivational and Volitional Processes in Sunscreen Use: A Longitudinal Online Experiment. Ph.D. Thesis, Free University of Berlin, Berlin, Germany, 2010. Available online: http://www.diss.fu-berlin.de/diss/receive/FUDISS_thesis_000000020465 (accessed on 31 May 2012).

16. Hevey, D.; Dolan, M. Approach-inhibition disposition moderates the effects of framing skin cancer information on affective responses. Psychol. Health 2008, 23(Suppl 1), 141-142.

17. Kang, H. The Influence of Fear Appeal on Persuasion Effects for Skin Cancer Public Service Announcements (PSAs) According to Fear Message Framing and Fear Type. Presented at The Conference of the Association for Education in Journalism and Mass Communication, St. Louis, MO, USA, 10-13 August 2011.

18. Rothman, A.J.; Salovey, P.; Antone, C.; Keough, K.; Martin, C.D. The influence of message framing on intentions to perform health behaviors. J. Exp. Soc. Psychol. 1993, 29, 408-433.

19. Lemieux, R.; Hale, J.L.; Mongeau, P.A. Reducing Risk Behaviors Related to Sun Exposure: The Effects of Fear Appeals, Vividness, and Message Framing. Presented at The Annual Meeting of the Speech Communication Association, New Orleans, LA, USA, 18-22 November 1994.

20. Block, L.G. The Effects of Perceived Efficacy, Message Framing and Vividness on the Persuasiveness of a Fear Appeal. Ph.D. Thesis, Columbia University, New York, NY, USA, 1993.

21. Block, L.G.; Keller, P.A. When to accentuate the negative: The effects of perceived efficacy and message framing on intentions to perform a health-related behavior. J. Mark. Res. 1995, 32, 192-203.

22. Cho, H.; Sands, L. Gain- and loss-frame sun safety messages and psychological reactance of adolescents. Commun. Res. Rep. 2011, 28, 308-317.

23. Hwang, Y.; Cho, H.; Sands, L.; Jeong, S.H. Effects of gain- and loss-framed messages on the sun safety behavior of adolescents: The moderating role of risk perceptions. J. Health Psychol. 2011, doi:10.1177/1359105311428536.

24. Hevey, D.; Pertl, M.; Thomas, K.; Maher, L.; Craig, A.; Chuinneagáin, S.N. Body consciousness moderates the effect of message framing on intentions to use sunscreen. Int. J. Psychol. 2008, 43, doi:10.1080/00207594.2008.10108483. 
25. Hevey, D.; Pertl, M.; Thomas, K.; Maher, L.; Craig, A.; Chuinneagáin, S.N. Body consciousness moderates the effect of message framing on intentions to use sunscreen. J. Health Psychol. 2010, $15,553-559$.

26. Thomas, K.; Hevey, D.; Pertl, M.; Chuinneagáin, S.N.; Craig, A.; Maher, L. Appearance matters: The frame and focus of health messages influences beliefs about skin cancer. Br. J. Health Psychol. 2011, 16, 418-429.

27. Hoffner, C.A.; Ye, J. News about Sunscreen and Skin Cancer: The Role of Framing and Social Comparison. Presented at The Annual Meeting of the International Communication Association, New Orleans, LA, USA, 27-31 May 2004.

28. Hoffner, C.A.; Ye, J. Young adults' responses to news about sunscreen and skin cancer: The role of framing and social comparison. Health Commun. 2009, 24, 189-198.

29. Nan, X. Influence of Incidental Affect and Message Framing on Persuasion: The Case of promoting sun Protection Behaviors. Presented at The Annual Conference of the Association for Education in Journalism and Mass Communication, Chicago, IL, USA, 6-9 August 2008.

30. Nan, X. Influence of incidental affect and message framing on persuasion: The case of promoting sun protection behaviors. Int. Pub. Health J. 2011, 3, 111-121.

31. Seo, K.W. Effects of Visual Images in Health Message Framing. M.S. Thesis, Pennsylvania State University, University Park, PA, USA, 2008. Available online: https://etda.libraries.psu.edu/ paper/8704/4021 (accessed on 31 May 2012).

32. Seo, K.; Shen, F. The Interactive Effects of Visual Images and Message Framing on HealthRelated Persuasion. Presented at The Annual Conference of the International Communication Association, Chicago, IL, 21-25 May 2009.

33. Shamaskin, A. Getting the Message Across: Examining Information Presentation and Healthcare Decision Making among Older Adults. Undergraduate Honors Thesis, Human Development, Cornell University, Ithaca, NY, USA, 2009. Available online: ecommons.cornell.edu/bitstream/ 1813/12656/1/THESIS.doc (accessed on 31 May 2012).

34. Shamaskin, A.M.; Mikels, J.A.; Reed, A.E. Getting the message across: Age differences in the positive and negative framing of health care messages. Psychol. Aging 2010, 25, 746-751.

35. Shen, L. The Interplay of Message Framing, Cognition and Affect in Persuasive Health Communication. Ph.D. Thesis, University of Wisconsin-Madison, Madison, MI, USA, 2005.

36. Shen, L.; Dillard, J.P. The influence of behavioral inhibition/approach systems and message framing on the processing of persuasive health messages. Commun. Res. 2007, 34, 433-467.

37. Stoner, S.A. Goal Framing of Health Related Behaviors: What Factors Contribute to the Persuasiveness of a Message? Ph.D. Thesis, West Virginia University, Morgantown, WV, USA, 2010.

38. Stoner, S. Goal framing of health related behaviors: What factors contribute to the persuasiveness of a message? Gerontologist 2009, 49(Suppl. 2), 115.

39. Borenstein, M.; Rothstein, H. Comprehensive Meta-Analysis, Version 2.2.023; Biostat: Englewood, NJ, USA, 2005.

40. Cox, A.D.; Cox, D.; Zimet, G. Understanding consumer responses to product risk information. J. Mark. 2006, 70, 79-91. 
41. Currie, S.A. The influence of Message Framing and Health Locus of Control upon Intentions to Using Sunscreen. Undergraduate Thesis, Department of Psychology, University of Stirling, Stirling, Scotland, UK, 2010.

42. Detweiler, J.B.; Bedell, B.T.; Salovey, P.; Pronin, E.; Rothman, A.J. Message framing and sunscreen use: Gain-framed messages motivate beach-goers. Health Psychol. 1999, 18, 189-196.

43. Fischer, J.C.; Nabi, R. Priming Frames: Can Framing Effects Extend Beyond Message Topic? Presented at The Annual Meeting of the International Communication Association, Washington, DC, USA, 24-28 November 2001.

44. $\mathrm{Ku}, \mathrm{A} . \mathrm{W}$. The Impact of Health Advertising on Health Risk Perceptions and Behavioural Intention. M.S. Thesis, University of Guelph, Guelph, ON, Canada, 2008.

45. Lee, A.Y.; Aaker, J.L. Bringing the frame into focus: The influence of regulatory fit on processing fluency and persuasion. J. Pers. Soc. Psychol. 2004, 86, 205-218.

46. Lee, C.K.-C.; Brown, R.; Blood, D. The effects of efficacy, cognitive processing and message framing on persuasion. Australas. Mark. J. 2000, 8, 5-17.

47. McCormick, M. Does Lateral Attention Affect Health Behavior?: Investigating Hemispheric Influences in Framed Health Messages. M.S. Thesis, University of North Carolina at Greensboro, Greensboro, NC, USA, 2010.

48. Robinson, N.G. Young Women's Sun-protective Attitudes and Behaviours: The Role of Social Influence Factors. Ph.D. Thesis, Queensland University of Technology, Brisbane, Australia, 2004. Available online: http://eprints.qut.edu.au/16042/1/Natalie_Robinson_Thesis.pdf (accessed on 31 May 2012).

49. Saadi, Y.M. Policy and Prevention: An Analysis of the Effectiveness of Contingency-based Intervention on the Adoption of Cancer Screening Behavior. Undergraduate Thesis, University of Pittsburgh, Pittsburgh, PA, USA, 2009.

50. Schubert, B.L. A UV Protection Intervention for Skin Cancer Prevention. Undergraduate Honors Thesis, Department of Psychology, Florida State University, Tallahassee, FL, USA, 2008.

51. Shen, L.; Kollar, L.M. Searching for Moderators of Message Framing Effect: A Motivational Approach. Presented at The Annual Conference of the National Communication Association, New Orleans, LA, USA, 17-20 November 2011.

52. Smith, L.L. Communicating Effective Skin Cancer Messages. Presented at The International Communication Association Conference, San Diego, CA, USA, 23-27 May 2003.

53. Taber, J.M. Hypothetical Genetic Disease Risk Moderates the Effect of Message Framing on Sunscreen Attitudes and Intentions. M.S. Thesis, University of Utah, Salt Lake City, UT, USA, 2010. Available online: http://content.lib.utah.edu/cdm4/document.php?CISOROOT=/usetd2\&CISOPTR=199116 (accessed on 31 May 2012).

54. Lipsey, M.W.; Wilson, D.B. Practical Meta-Analysis; Sage Publications: Thousand Oaks, CA, USA, 2001; pp. 138-140.

55. Hedges, L.V.; Pigott, T.D. The power of statistical tests in meta-analysis. Psychol. Methods 2001, 6, 203-217.

56. Ioannidis, J.P. Why most published research findings are false. PLoS Med. 2005, 2, 696-701.

57. Ioannidis, J.P. Contradicted and initially stronger effects in highly cited clinical research. JAMA 2005, 294, 218-228. 
58. Jackson, S. Message Effects Research: Principles of Design and Analysis; Guilford Press: New York, NY, USA, 1992.

59. Jackson, S.; Brashers, D. $\mathrm{M}>1$ : Analysis of treatment $\mathrm{x}$ replication designs. Hum. Commun. Res. 1994, 20, 356-389.

60. Jackson, S.; Jacobs, S. Generalizing about messages: Suggestions for design and analysis of experiments. Hum. Commun. Res. 1983, 9, 169-181.

(C) 2012 by the authors; licensee MDPI, Basel, Switzerland. This article is an open access article distributed under the terms and conditions of the Creative Commons Attribution license (http://creativecommons.org/licenses/by/3.0/). 